\title{
La experiencia cinematográfica: cine y mente
}

\author{
Vicente Castellanos Cerda*
}

\section{Presentación}

Desde los primeros años del invento del cine ya se perfilaban ciertas posturas teóricas con la finalidad de entender este nuevo medio. Los primeros usos, como deseaban los hermanos Lumière, encaminaron al cine a ser parte de las herramientas científicas que han ayudado en el estudio del movimiento de los cuerpos. Esta postura fue evidente en las innumerables películas de la vida cotidiana, sin pretensiones artísticas o narrativas, que registraron este par de hermanos con su famoso cinematógrafo. Virgilio Tosi manifiesta que el cine científico nació mucho antes que el de entretenimiento; de hecho este medio es heredero de dos orígenes científicos "dentro del campo de la investigación de la persistencia en la retina y en el desarrollo técnico de la fisiología del movimiento" (Tosi, 1987, p.13). Incluso, treinta y cinco años después de la histórica primera proyección en el Gran Café de París, se le preguntó a Louis Lumière su opinión acerca del cine, respondió que ni siquiera asistía a las salas de proyección, pues si hubiera sabido en lo que se convertiría, no lo habría inventado.

La curiosidad científica por el movimiento per se, rápidamente se agotó. Entonces el cine se unió a los espectáculos y diversiones propios de principios del siglo XX: el circo, la feria y el vodevil. Uno que otro aventurado camarógrafo ya no se limitaba a ofrecer a la gente de una comunidad la posibilidad de re-conocerse en una pantalla de sombras grises, por el contrario, ahora se mostraba un breve relato, generalmente humorístico, donde se construía un mundo ficcional, a veces alejado del entorno de los primeros espectadores. El cine como espectáculo masivo se consolidaba a la vez que desplazaba sus posibles usos científicos.

Al mismo tiempo, una elite de intelectuales, revolucionarios y artistas, vieron en el nuevo medio un campo virgen para la experimentación artística. Las vanguardias de la primera parte del siglo XX incluyeron al cine en sus manifiestos y creaciones, algunos incluso lo elevaron sobre las artes clásicas, por el hecho de fusionar

*Universidad Nacional Autónoma de Mćxico

Universidad del Valle de México 
tanto las artes del espacio como del tiempo. Los acercamientos teóricos avanzaban conforme se descubrían las diversas posibilidades de expresión del nuevo medio, así se escribió sobre la relación entre cine y música, cine y realidad, cine y experiencia onírica, cine y pintura.

En suma, los primeros años del cine originaron una producción teórica que buscaba ubicarlo en algún tipo de uso social. Tres fueron los caminos: el cine científico, el cine espectáculo y el cine arte.

En 1916, justo un poco antes de morir, tras asistir regularmente durante 10 meses a las salas de cine y después de una serie de entrevistas con actores y directores de la época, un psicólogo de origen alemán, Hugo Münsterberg ', desarrolló una de las más sincréticas y útiles tesis sobre la experiencia cinematográfica, primero al ubicar el origen del cine dentro del campo de los experimentos de la percepción del movimiento y, posteriormente, al analizar la situación psicológica del espectador. El estudio es importante no sólo porque fue el primer acercamiento teórico sobre el film como un modelo de funcionamiento de la mente humana, sino también porque caracterizó la impresión de realidad que produce el cine desde un punto de vista estético.

El planteamiento de Münsterberg separa al cine de su aparente dependencia con el teatro y reflexiona acerca del trinomio cienciaespectáculo-arte a favor de la comprensión de los procedimientos mentales de la experiencia cinematográfica, principalmente las que genera el cine narrativo.

En el fondo, el planteamiento consiste en un cambio de perspectiva acerca de las capacidades de percepción y comprensión de una película por parte del espectador. Ocuparse del cine, es también ocuparse de las facultades subjetivas surgidas por la acción recíproca entre un sujeto que construye un objeto y otro lo que lo recibe en el marco de una cultura cinematográfica caracterizada por una nueva sensiblidad y un novedoso pensamiento. Esta idea es precisamente la que pretendemos rescatar como objetivo del presente trabajo, pues con el inicio del cine se evidenció la necesidad de explicaciones más

El texto no ha sido traducido al español. A continuación se mencionan los datos de la primera edición del original escrito en inglés: Münsterberg, Hugo (1916). The Photoplay: A Psychologial Study. D. Appleton \& Co. New York. Una segunda reimpresión aparece hasta 1970 , misma que fue retomada para este trabajo. Finalmente, en el año 2002, el profesor de la Universidad de California, Allan Langdale, edita una vez más el libro y agrega una nota bibliográfica de Münsterberg y otros textos previos al Photoplay. 
profundas de las relaciones del espectador con el pensamiento, la emoción y la sensibilidad movilizadas por una película. El hecho de dar cuenta de los procesos de estructuración de un objeto estético (el film) y de sus respectivos efectos en la construcción de significados, nos condujo a ese cambio de mirada, siempre con el espíritu de rescatar o replantear las explicaciones que se han dado de una de las formas culturales más complejas de nuestro tiempo.

Por el momento, nuestra posición es la de un espectador primitivo, que a la manera de las nacientes proyecciones, deseaba comprender cómo las secuencias de acciones conducían a los personajes de una situación a una situación prima, cómo partes de cuerpos se transformaron en nuestra mente en personas completas, cómo fragmentos temporales y espaciales se unieron sin ni siquiera haber aparecido en la pantalla. En fin, intentamos conocer cómo nuestras limitantes perceptivas son superadas por el funcionamiento de nuestra mente.

\section{Condiciones ambientales, perceptivas y psicológicas de la experiencia cinematográfica}

A partir de los años treinta del siglo XIX se desarrolló un verdadero laboratorio en Europa y Estados Unidos que daba cuenta de la impresión del movimiento: el estroboscopio, el daedaleum, el nickelodeum, el zootropo y, casi al finalizar ese siglo, el kinetoscopio y cinematógrafo. Todos experimentos para el control y la producción de la imagen móvil. Paralelo a esos experimentos, apareció la necesidad de explicar cómo imágenes fijas se percibían móviles a cierta velocidad y bajo ciertas condiciones de recepción. Ambos hechos condujeron a la puntualización de las condiciones ambientales, fisiológicas y psicológicas del cine.

A esta nueva clase de condición mental, Hugo Münsterberg la llamó photoplay. Si bien esta noción se puede confundir con la expresión de teatro filmado, aunque con ciertas características que lo alejan de la puesta en escena dramática, el psicólogo alemán realmente se refirió al vocablo play en su acepción de ejecución, de transcurso y duración, no de representación. En el corazón del photoplay, como él mismo afirmó, se encuentra una serie de fotografías planas, en contraste con los objetos de la plástica tridimensional del mundo que nos rodea, pero que tiene una fuerte impresión de realidad. Así la percepción tridimensional, la impresión de movimiento y las condiciones adecuadas para la proyección del material traslúcido sobre 
una pantalla blanca, se convierten en los tres primeros elementos que ayudan a explicar la experiencia cinematográfica.

La percepción tridimensional tiene su origen en la visión estereoscópica de la mirada binocular del ser humano. Cada ojo ve ligeramente diferente y esa asimetría permite percibir la dimensión espacial, incluso en imágenes que carecen de ella, aunado a esto se encuentra la forma de representación renacentista que tiende a expandir la mirada hacia el fondo.

En lo referente a la impresión de movimiento, la teoría de la persistencia retiniana cada vez es más endeble respecto al fenómeno phi, tal vez por la facilidad con el que este último se comprueba: la cinta expuesta y revelada de una película está dividida por líneas negras que alcanzan un punto de fusión a determinada velocidad ${ }^{2}$, cada línea interrumpe el estímulo y el cerebro percibe la luz como estable y continua.

Respecto a las condiciones adecuadas se sabe que éstas tienen una justificación ambiental que preparan al espectador para cierto tipo de aislamiento, necesario para establecer una relación íntima con la película. Pero, la pantalla impone límites a la visión, por lo regular el espectador huye de los extremos, sean laterales o verticales, de tal forma que su punto de vista empate con el de la cámara. El espectador necesita convertirse en el lente con la finalidad de crear una condición adecuada de percepción. Revisemos este primer acercamiento de manera esquemática.

\section{Percepción y condiciones de la experiencia cinematográfica}
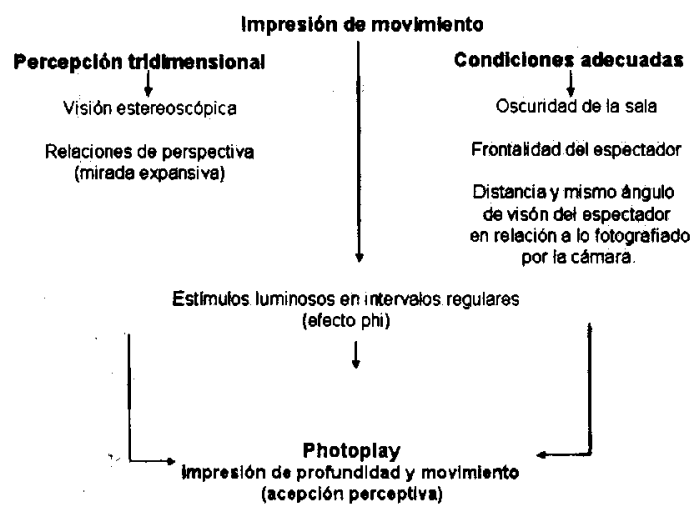

${ }^{2}$ En términos generales, se han expuesto 16, 18624 cuadros por segundo a lo largo de la historia del cine. La sensación de movimiento más cercana a la realidad es la de 24 . 
Ahora bien, la inmovilidad y la carencia de tercera dimensión del cine son fenómenos innegables, pero sólo son una parte del photoplay, pues también existe un componente psicológico, mental en términos de Münsterberg. Al respecto, el teórico estadounidense, Dudley Andrew, sintetiza este pensamiento: "La maquinaria compleja (cámaras, proyectores y todo el mecanismo del proceso), al producir imágenes fijas intermitentes, ha sido desarrollada para trabajar directamente sobre la materia prima de la mente. El resultado es el cine" (Andrew, 1978: 29).

El mecanismo mental del cine subordina la función científica y didáctica - idea original de los Lumière - y la sustituye por la de entretener y sorprender a las masas. El photoplay desde sus orígenes estuvo vinculado a la rápida pérdida de interés por mostrar la vida diaria, por difundir una curiosidad científica, e incluso, por dar a conocer los grandes hechos históricos. Ya en 1916, el público demand6 al cine contar historias, incluso el propio Münsterberg afirmó que el cine no narrativo era tan sólo un accidente mecánico.

Aunado al efecto de realidad que produce la profundidad y el movimiento, con el cine narrativo inició uno de los debates teóricos fundadores del cine, hablamos del problema de la representación, desde dos enfoques contrarios: como reproducción de la realidad, o bien, como modelo de un universo autosuficiente.

Hay tres anécdotas muy conocidas respecto a las reacciones de los primeros espectadores del cine que explican claramente el problema de la representación, antes que cualquier teoría lo considerara. Mencionemos primero dos que se relacionan con la representación mimética de la realidad, es decir, con aquella facilidad del cine para conservar la fe del espectador en la autenticidad de lo que ve y oye. En el Moscú posrevolucionario una muchacha de la región de Siberia que casualmente no había asistido a una sala cinematográfica, al salir por primera vez de una proyección se le preguntó su opinión sobre la película, la respuesta fue desconcertante para aquellos años: “ $i E s$ horrible! -dijo indignada-. No puedo entender cómo en Moscú dejan exhibir tales horrores (...) He visto cómo partían personas en pedazos. La cabeza, los pies, las manos estaban fuera de lugar" (Balázs, 1978, p. 30). Otro ejemplo, anterior y tal vez por eso más comprensible: las crónicas periodísticas acerca de las primeras proyecciones del cinematógrafo en París, relataban las reacciones de los asistentes al ver La llegada del Tren a la estación (1895, Hermanos Lumière), pues se cubrían con las manos los ojos o brincaban de sus sillas al 
precipitarse la imagen del tren sobre ellos. Este último efecto fue consecuencia del emplazamiento de la cámara, en perspectiva lineal y en dirección contraria al viaje del tren ${ }^{3}$.

La tercera anécdota se halla en el otro extremo de la representación, es decir, en aquel que desnuda el dispositivo cinematográfico y advierte la sórdida irrealidad del cine: su falta de olor, de volumen, de sonido y de color, expuesta puntualmente por el escritor Máximo Gorki en 1896:

La noche pasada estuve en el Reino de las Sombras. Si supiesen lo extraño que es sentirse en él. Un mundo sin sonido, sin color. Todas las cosas -la tierra, los árboles, las gentes, el agua y el aire- están imbuidas allí de un gris monótono. Rayos grises de sol que atraviesan un cielo gris, grises ojos en medio de rostros grises y, en los árboles, hojas de gris ceniza. No es la vida, sino su sombra, no es el movimiento, sino su espectro silencioso (Gorki en Montiel, 1992: 16).

Para Gorki un film traiciona la vida real, la falsea bajo el halo de un gris monótono y de un movimiento espectral. Para él la imagen del cine no es reproducción mecánica de la realidad, sino sólo su sombra por lo que ninguna emoción humana es posible.

Alrededor de cincuenta años más adelante, el fundador de la Escuela de Tartu, el estoniano Yuri Lotman, señaló que el problema de la representación en el cine no es una guerra de opuestos, más bien son condiciones necesarias, aunque contradictorias, para que el espectador asista a la sala de cine.

La imagen fotográfica y la visión estereoscópica con su impresión de profundidad, someten el film al automatismo de la reproducción técnica y provocan el llamado efecto de realidad. Al respecto, Lotman encuentra una ingeniosa explicación en la teoría de la información desarrollada a lo largo de la primera mitad del siglo XX en Estados Unidos, ya que los mensajes portadores de información artística son aquellos caracterizados por cierto grado de indeterminación, es decir, que potencializan las alternativas en la generación de significados. Así, la fotografía hace descender el grado de indeterminación del

${ }^{3}$ Algunos investigadores sostienen que el público de los primeros años no era tan ingenuo como para confundir las imágenes con la realidad. Más bien, el asombro y sobresalto se explica por la propia naturaleza de la ilusión cinematográfica, al respecto véase Gunning en Darley, 2002: 82. 
film, alejándolo del arte, pero la formación de ciertos dispositivos específicos del cine lo han separado del automatismo: la autorreferencialidad del cine moderno, el uso del color y del blanco y negro ${ }^{4}$, pero sobre todo la estructura narrativa del cine hollywoodense clásico.

En resumen, el cine oculta o transparenta su dispositivo narrativo para conservar la fe del espectador en que lo que ve es auténtico: «La ficción me hará derramar lágrimas» (Pushkin en Lotman, 1973: 25), es decir, por un lado aceptamos el mundo de sombras y de ilusión de movimiento como una prolongación de la experiencia vivida de manera cotidiana, pero, al mismo tiempo, estamos conscientes de la ficcionalidad del film. Y es precisamente en la toma de conciencia de esta convencionalidad donde radica otro elemento que conduce a entender la experiencia cinematográfica.

Sin la posibilidad de aceptar la irrealidad de lo que ocurre al observar una realista pantalla de cine, ningún espectador podría disfrutar la actuación de un asesino serial, la destrucción de la tierra, la miseria humana, el amor imposible, el viaje redentor, el dominio de la humanidad por parte de las máquinas, incluso los documentales de guerra o los noticiarios cinematográficos serían motivo de horror y de dolor. El olvidar la ficción de la película, pero al mismo tiempo no olvidarla, permite separar el cine de la realidad y acercarlo al funcionamiento de la mente.

\section{De la percepción a las formas internas de la mente: atención, memoria e imaginación}

El reconocimiento de los mecanismos perceptivos y ambientales son insuficientes para entender cómo el cine y la mente funcionan, pues el cine narrativo también enriquece nuestra imaginación, despierta los remanentes de nuestra vida más temprana, aviva nuestros sentimientos y emociones, en pocas palabras, atrae nuestra atención. El caos de las impresiones cinematográficas es organizado por el universo real de la experiencia con base en lo que es significativo y

${ }^{4}$ Se podría pensar que el color aumenta el automatismo del cine, sin embargo, gracias a las convenciones y a los usos históricos del blanco y negro en el cine moderno y contemporáneo, se pueden encontrar filmes que intercalan el blanco y negro en los momentos de mayor realismo, por ejemplo, en una película de guerra, las escenas del campo de batalla suelen proyectarse de esta manera. Al parecer el color está vinculado con el argumento de la ficción y el blanco y negro con la realidad del documental. 
tiene alguna con frecuencia para nosotros. En una película nos podemos interesar por la vida de los personajes, por el escenario, por la música, por el movimiento de la cámara. Sin embargo, existe una segunda atención involuntaria propia de este arte que nos obliga a naufragar a lo largo del flujo de las imágenes-movimiento: el primer plano. ¿Cómo escapar a la tiranía del primer plano? El todo se reduce a un rostro, a un objeto, a un fragmento imposible de eludir: "Aquí empieza el arte del photoplay. (...) El detalle que se está viendo se convierte repentinamente en el volumen entero de la actuación y cada cosa que nuestra mente quiere desatender se ha desterrado de repente de nuestra vista y ha desaparecido" (Münsterberg, 1970: 87).

El photoplay invita a la atención voluntaria (¿qué tiene sentido para nosotros?) e involuntaria (primer plano) bajo las siguientes características:

1. Cualquier estímulo sensorial proveniente de la película es para el espectador una experiencia intensa de vida.

2. Un efecto de esta atención profunda es que inhibe el todo, por eso la experiencia cinematográfica es siempre una experiencia del detalle, por el ejemplo el primer plano.

3. El cuerpo se ajusta a la atención: movemos la cabeza al ritmo de un sonido, tensionamos los músculos ante una escena de suspenso, incluso, hay quien grita.

4. Nuestras ideas y sentimientos se agrupan alrededor del objeto resaltado, mientras que el entorno pierde interés.

Ahora bien, la mente no sólo funciona porque focaliza la atención, sino también por la posibilidad específicamente humana de recordar e imaginar. Si el primer plano es una característica del desprendimiento de la cámara del punto de vista teatral, la memoria y la imaginación son inherentes al montaje cinematográfico.

Así como el cine fragmenta el espacio, también rompe la continuidad objetiva del tiempo para constituirse en pasado y futuro a la vez, es decir, en memoria y fantasía. Las regresiones de un personaje se viven como propias del mecanismo mental: uno decide cuándo y qué recordar sin importar la situación del presente. Del mismo modo, el espectador construye expectativas, se imagina la acción siguiente, actualizada o no en la pantalla. Es el terreno del deseo: un personaje se imagina la huida y la felicidad desde una celda, también el espectador lo hace desde su butaca, pues se adelanta a la 
acción, se plantea hipótesis que pretende sean corroboraras en secuencias posteriores. El photoplay originó un verdadero inventario de actividades mentales, revisémoslas a continuación para después hacer referencias a ellas.

\section{Inventario de las actividades mentales producidas por el photoplay}

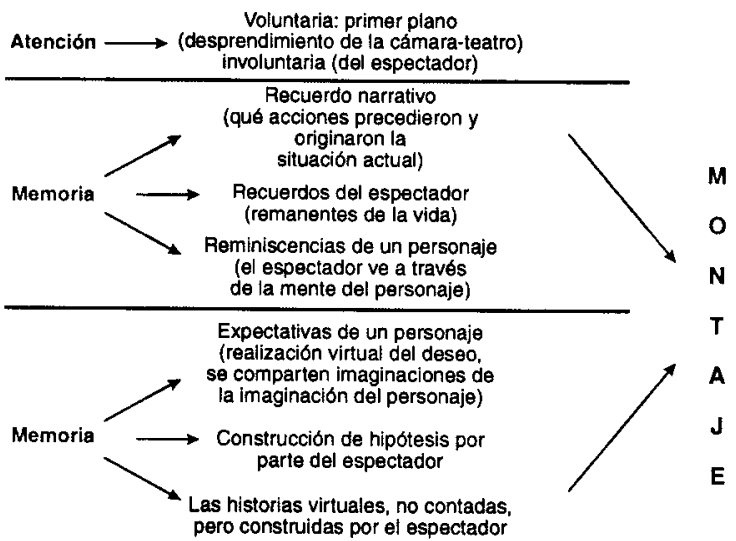

Según este inventario el espectador recuerda e imagina no sólo a través de los personajes, sino también gracias a sus propias inquietudes. Al mismo tiempo que el espectador se identifica con la vida de los personajes, el photoplay despierta la conciencia, el mundo subjetivo que activa la historia y los deseos personales. En este sentido, el cine funciona como nuestra mente al consagrarse simultáneamente a varios conjuntos de imágenes e ideas. La percepción de profundidad, de movimiento, así como los actos de atención, memoria e imaginación muestran que el mundo objetivo se amolda a los intereses de la mente. El cine muestra eventos que están lejos entre sí, distantes unos de otros, sin embargo, los tenemos fusionados en nuestro campo de visión, como si los reuniera nuestra propia conciencia.

Estos procedimientos lógicos del espectador para establecer relaciones entre la pantalla y su vida, así como la capacidad de ligar acciones subsecuentes de acuerdo a la naturaleza de la narración cinematográfica, representan la parte intelectiva del photoplay. Realmente se trata de una actividad mental de dos planos, pues el interés siempre surge de la pantalla y es la mente quien escinde la atención hacia la literalidad del sentido que transmite la imagen o hacia las emociones con las que responde el espectador. 
Si regresamos al esquema original para sumarle las formas internas de la mente, la experiencia cinematográfica desde el punto de vista psicológico se podría resumir de la siguiente manera:

\section{El photoplay: experiencia psicológica del cine}

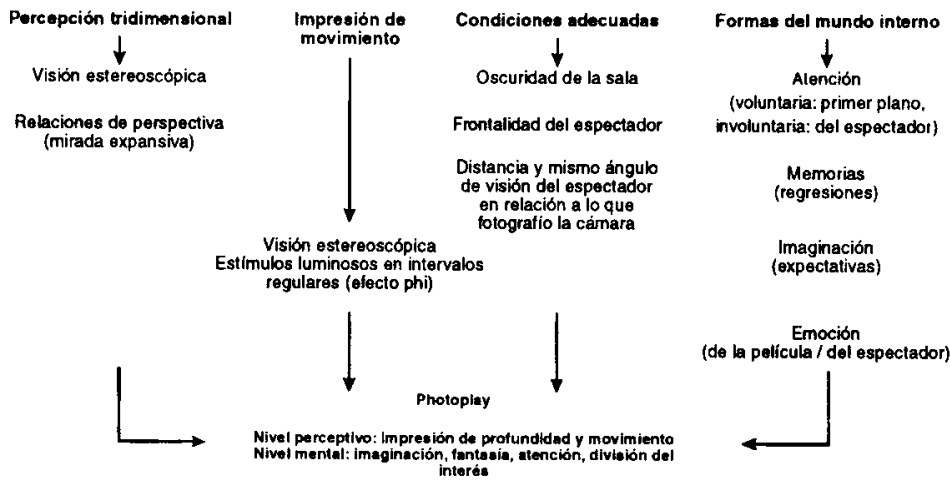

Ahora bien, cada arte tiene sus propios medios y formularios para separar la experiencia artística de la experiencia cotidiana. El esquema anterior resume los propios del photoplay que no son otra cosa que los movimientos internos de la mente. El espectador percibe dos dimensiones y una sensación de movimiento, pero es la mente la que amolda esos cuadros planos a la realidad plástica-tridimensional.

Con lo dicho hasta el momento se puede definir de modo muy concreto al cine como sigue: "El photoplay nos habla de la historia humana, superando las formas del mundo exterior, llamadas: espacio, tiempo y causalidad, y ajustándolas a los eventos de las formas del mundo interior, llamadas: atención, memoria, imaginación y emoción" (Münsterberg, 1970: 173). De las formas del mundo externo, conviene detenernos en la de la causalidad, pues nos permite, ahora por negación, acercarnos aún más a la condición psicológica del cine. Pensemos en la siguiente sucesión de imágenes proyectadas en la pantalla: el cuerpo de un hombre yace en el suelo, de repente éste se levanta de manera poco natural: hacia atrás y sin apoyarse con las manos, un detalle de la cámara nos acerca a una bala que viaja a gran velocidad, pero para nosotros su movimiento es visible porque la vemos " $n$ " número de veces más lenta. La bala prácticamente está suspendida en el espacio, pero sigue moviéndose no en sentido lógico, pues en lugar de ir hacia delante, se niega a ser la causa de un disparo 
y dibuja una travesía en sentido contrario. De un momento a otro la bala desaparece dentro de la boca de un revólver. A continuación vemos la mano que sostiene el arma y un dedo que afloja un gatillo en lugar de empujarlo. Por último, la mano con la pistola hace un movimiento semi-circular hacia arriba. Fin de la secuencia. ¿Qué nos muestran estas imágenes? La relatividad del principio lógico de la causalidad y el cuestionamiento de la idea de absoluto. Toda secuencia proyectada al revés evidencia un antiuniverso propio de las particularidades del cine, en este caso, la bala es atraída y no expulsada por el revólver, un hombre desafía la gravedad y la muerte. Con esta particularidad del cine hemos aprendido a reconocer la antípoda de la causalidad, su contrario, tal vez el efecto convertido en causa en un mundo nuevo y relativo. La enseñanza radical de la cámara al revés es mostrarnos la apariencia de toda causa y la esencia del azar, del caos, de las relaciones arbitrarias que construimos los seres humanos para ordenar la complejidad del entorno natural y social. El húngaro Béla Bálazs vio en las formas particulares del cine no una esencia científica, sino una esencia estética: "El film no sólo mostró otras cosas, sino que lo hizo de otra manera, sustrajo constantemente la conciencia del espectador, eliminando la distancia interior que hasta entonces pertenecía a la esencia de la experiencia estética" (Bálazs, 1978: 39).

Esta máquina nacida en el siglo XIX, a veces disminuida en sus efectos estéticos y sociales tanto por cineastas, públicos y teóricos, ha demostrado ser un instrumento de modelización del espacio y del tiempo. Su papel no se ha limitado a fotografiar objetos o a contar innumerables historias. Por el contrario, el cine puede mostrar esa otra manera de las cosas a las que se refiere Bálazs debido a su dispositivo técnico que es posible englobar en tres grandes macrocategorías formales: la puesta en escena, la puesta en cuadro y la puesta en serie.

La puesta en escena (mise en scène) está conformada por todo lo que aparece frente a la cámara previamente colocado y jerarquizado. Cada elemento puede devenir en signo, en una unidad de sentido. Responde a la pregunta, ¿qué se filma?.

La puesta en cuadro (mise en shot) se refiere a los múltiples parámetros de la cámara y el sonido controlados directamente por el director o por un equipo creativo y técnico. Responde a la pregunta, ¿cómo se filma?

La puesta en serie (montage) consiste en la combinación de 
planos donde el espacio y el tiempo se reestructuran en términos cinematográficos. Responde a la pregunta: ¿cómo se ordenan las tomas y las secuencias de la película?

¿Qué nos dicen estas primeras reflexiones teóricas del fenómeno cinematográfico? Nos recuerdan que de alguna manera tanto el uso de la cámara como de cualquier otro elemento técnico-expresivo del cine, ya habían sido empleados en los primeros años de esta fabuloso mecanismomáquina. Asimismo, reconocemos que los grandes temas ontológicos no han cambiado en mucho en 85 años de estudios del cine.

Ahora bien, hasta aquí hemos caracterizado a este medio en dos dimensiones: en una dimensión paradójica (el cine como una realidad de suma de irrealidades) y una dimensión mental (el cine como las formas del mundo interno del hombre). También esbozamos una tercera: la del mecanismo-máquina que se supera para convertirse en el único arte que el hombre contemporáneo vio nacer. Los tres temas, aún están presentes en las modernas teorías semióticas, lingüísticas o cognitivas del cine. Las conclusiones de los primeros estudios nos interesan porque evidencian los principios de organización del cine, resumidos en perspectivas de espacio y tiempo variables. Las coordenadas del hombre, se ven repentinamente fragmentadas y cuestionadas, pero se recomponen en la planificación y en el montaje del cine clásico, desarrollados desde 1915. Asimismo, el cine revolucionó la percepción del hombre del siglo $\mathrm{XX}$, hizo que el espectador volteara la vista a los detalles y a la no linealidad del tiempo. Al detalle porque, como afirma Bálazs, "es específico del arte cinematográfico no sólo el ver imágenes seleccionadas de la escena completa, los átomos de la vida desde cerca (una vida que nos muestra sus secretos más íntimos), sino también la conservación de la intimidad de los detalles" (Bálazs, 1978: 27). Por su parte, el tiempo se convirtió en materia expresiva que el mecanismo-máquina podía moldear en una nueva forma, ahí estaban las potencias, sólo hacía falta descubrirlas. Desde entonces comenzó una emancipación del tiempo cinematográfico respecto al tiempo vivido y que Münsterberg los caracterizó como fenómenos de la memoria y de la imaginación.

En este sentido, una primera conclusión podría permitirnos una reconsideración del cine como una máquina inteligente, por supuesto, no afirmamos que piense o sienta como los seres humanos, sino que es capaz de movilizar intercambios de significados afectivos y racionales entre dos intérpretes, entre el director o el grupo de producción y el espectador se establece una semiosis ilimitada de 
reenvíos sígnicos. Se podría hablar de una máquina semiótica que aquí hemos comenzado a comprender, no en el nivel del lenguaje natural, sino en la posibilidad del cine de revelarnos otras cosas y otras condiciones de esas cosas. El cine nos advirtió sobre un mundo inestable, prácticamente onírico, en oposición al mundo lógico, sostenido en las leyes de la causalidad; por otro lado, nos exhibió nuevas relaciones espacio-temporales bajo una perspectiva múltiple y variada. Todo esto restituye una experiencia profundamente real sobre un mecanismo extremadamente irreal. El cine fue la primera máquina inteligente, pero también fue la primera que expresó la sensibilidad del hombre contemporáneo: "En el caso del cinematógrafo no sólo existe una sensibilidad particular y múltiple, sino también un poder muy variado de combinar y transformar los datos de dicha sensibilidad, de todo lo cual resulta una especie de actividad psíquica, de vida subjetiva, que prepara y por lo mismo orienta el trabajo intelectual del hombre" (Epstein, 1960: 145). Ante tal panorama, hay que volver la vista al aparato cinematográfico para conocer de cerca el funcionamiento del cine y de la mente. En estos nos centraremos en los siguientes análisis.

\section{Análisis}

Las reflexiones teóricas acerca del cine parten, en todos los casos, de la experiencia directa con la película. Las conceptualizaciones cinematográficas son el resultado de una inquietud que se despertó a lo largo de la proyección. Münsterberg, cuyas ideas han guiado este trabajo, se encontró repentinamente sorprendido donde menos lo esperaba, ni su trabajo académico, ni sus reflexiones, ni sus prejuicios acerca del cine en 1916, lo obligaron a negarse a escribir la siguiente revelación:

\footnotetext{
"El año pasado, mientras viajaba a miles de millas de Boston, yo y un amigo nos arriesgamos a ver Neptune's Daughter, y mi conversión fue rápida. Reconocí por primera vez las posibilidades maravillosas que se abrian y comencé a explorar seriamente un mundo que era nuevo para mí". (Münsterberg en Langdale, 2002: 7-8).
}

La conversión no cesa de ser rápida en la experiencia con el cine, las posibilidades de una mirada renovada de las películas y de nuestro entorno, nos llevan a explorar el film, a saber más de él, a querer 
conocer los mecanismos por los cuales logra determinados efectos en nuestras conciencias.

Si bien, Münsterberg se sorprendió con un cine incipiente en su forma, el origen de la experiencia estaba sembrado. En la actualidad, lejos de haberse agotado, las películas continúan revelándonos mundos nuevos, y no nos referimos únicamente a los géneros de fantasía y ciencia-ficción, pues incluso en los filmes más figurativos, existen elementos que nos obligan a re-pensar la vida misma.

Por eso, aquí se rescata una tradición analítica inaugurada en los años sesenta por el filmolingüista Christian Metz (2002) y por el estudioso de temas psicológicos en el cine, Raymond Bellour (2002). No se trata de aplicar un modelo de análisis o de seguir puntualmente los hallazgos de estos dos pensadores franceses. Realmente la intención es más humilde, pues sólo se pretende recuperar el interés por el significante cinematográfico por encima del relato que transporta todo film de ficción. Esta actitud de ir directamente a las películas abre nuevas pistas para dar orden y coherencia al análisis del cine al incluir los hallazgos de una experiencia intensa de vida, como lo es el ver una película, en un marco más amplio de comprensión llamado regularmente teoría. Con esta actitud también deseamos ser cautelosos y no pensar que un modelo de análisis soluciona cualquier problema de estudio del cine, por el contrario, nuestra idea es privilegiar las propuestas teóricas y metodológicas en los contextos adecuados.

Las dos películas aquí analizadas parten de un fenómeno común propio de las grandes ciudades norteamericanas: la violencia. La temática es importante en la medida en que hace inteligible el film, pero en este trabajo estamos más interesados por la forma cinematográfica o por aquellos elementos que conducen nuestra atención, memoria e imaginación, es decir, queremos dar cuenta del funcionamiento del photoplay y la manera en que la inteligencia de esta máquina representa las relaciones espaciales, temporales y causales.

En este sentido, hay un claro objetivo que conduce el análisis:

Dilucidar el funcionamiento de la puesta en serie del cine a partir de ciertos mecanismos de la mente como son: la memoria, la emoción, la división del interés y la imaginación.

Para cumplir con esta meta, es necesario introducir dos categorías analíticas provenientes de los estudios de la literatura en combinación con otra estrictamente cinematográfica. Ya los formalistas rusos al 
referirse al estudio de los textos narrativos, habían planteado una distinción básica entre trama y fábula, aunque las discusiones han continuado hasta nuestros días, ambos conceptos se usan aquí en su acepción original dada a principios del siglo pasado.

La trama o syuzhet consiste en la organización artística de la película tal y como fue organizada por el director, esta estructura, ya no sólo narrativa sino también formal, produce un efecto en el espectador. Generalmente la trama del cine estadounidense ha estado subordinada a la transparencia narrativa, pero en los dos filmes aquí analizados no ocurre así y, precisamente, la organización estructural de los elementos formales cinematográficos es la que produce una visión renovada de nuestro entorno físico y social.

La fábula es un constructo del espectador a partir de la trama, consiste en la reorganización secuencial y cronológica de los acontecimientos. Es decir, mientras que la trama trabaja con las formas del mundo interior -de la mente-, la fábula lo hace con las del mundo exterior -de la realidad-, de ahí la importancia del pensamiento de Münsterberg.

La categoría formal pertinente para el análisis de las dos películas, es la de puesta en serie, pues el complejo montaje de ambos filmes estructura el espacio y el tiempo en términos cinematográficos más allá del uso simple del flash back. Las películas son: Pulp Fiction (Tiempos violentos) y Memento (Amnesia).

\section{Pulp Fiction ${ }^{5}$ el desorden en los bordes del relato}

Una de las primeras impresiones que causó este film de Quentin Tarantino fue la de cierta extrañeza, no por la opacidad de su propuesta temática, sino por la organización aparentemente azarosa de estructurar la película. Al respecto el famoso crítico estadounidense del Chicago Sun-Times, Roger Ebert, escribió: "Pulp Fiction se construye de tal manera no lineal, que usted podría verla una docena de veces y no podria recordar lo que viene luego" (Ebert, 1994, disponible en http:/ /www.suntimes.com/index/ebert.html). La cita no sorprende, pues Hollywood se ha encargado de hacernos creer que el cine es la vida misma, por supuesto, esta idea no sólo le conviene a un sistema económico de producción del cine, sino también al mantenimiento de ciertos presupuestos artísticos de organización de una película.

\footnotetext{
5icha técnica: Pulp Fiction (Tiempos violentos), Quentin Tarantino, Estados Unidos, 1994.
} 
En el fondo, la molestia de Ebert es su incapacidad por construir de manera rápida (recordemos que es periodista, no analista) una crítica de la película en términos lógicos, secuenciales y cronológicos. Desgraciadamente, Pulp Fiction requiere para su comprensión del análisis y no sólo de interpretaciones plausibles. Ahora bien, la construcción de la fábula es sencilla como lo demostramos a continuación.

La película está dividida en nueve grandes secuencias muy diversas en duración. Para revisar detalladamente cada una, no sólo hemos querido describirlas, sino también distinguirlas con líneas de formas diferentes. Las secuencias se pueden caracterizar del siguiente modo:

Texto: definición de Pulp, créditos iniciales, créditos finales.

..... Hace referencia a dos relatos indivisibles: el de Honey Bunny y Pumpkin / la de Vincent Vega y Jules Winfield.

= Secuencia de transición entre los dos relatos de Honey Bunny y Pumpkin/Vincent Vega y Jules Winfield y Marcelo Wallace y Butch.

ב Relato de Vincent Vega y Mia Wallace.

Relato de Marcelo Wallace y Butch.

Cabe hacer la aclaración que Tarantino divide explícitamente, letrero de por medio, su película de la siguiente forma:

1. Vincent Vega and Marsellus Wallace's Wife, aparece en el minuto veinte.

2. The Gold Watch, aparece a la hora con ocho minutos.

3. The Bonnie Situation, aparece a la hora con cincuenta y uno.

Esta división tripartita no es pertinente para la construcción de la fábula porque los letreros no coinciden con la cronología de las acciones. Por ejemplo, el relato del reloj de oro (The Gold Watch), inicia prácticamente cincuenta minutos antes que aparezca el letrero y la situación de Bonnie es una acción secundaria dentro del film, aunque en esta secuencia aparezca como personaje de apoyo el propio Tarantino.

De manera gráfica el desarrollo de la trama es el siguiente:

\section{Trama}

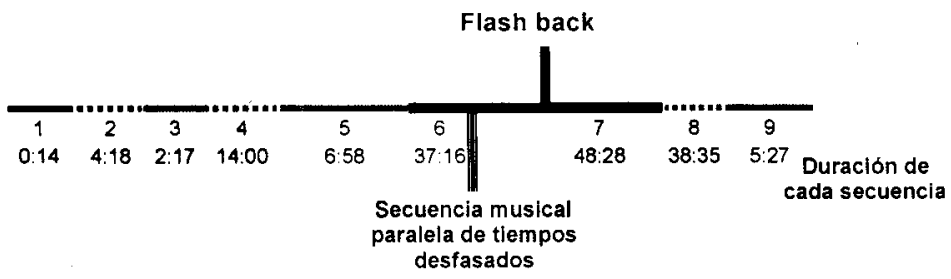


Las líneas simples (ـepresentan la aparición de tres tipos de textos: los créditos del inicio, del final y de un elemento poco común en las películas: una definición. El primer cuadro que ve el espectador es precisamente la definición de pulp o folletín que resume el tratamiento inverosímil y exagerado del film: "Novela que se acostumbra publicar en un periódico con sucesos y coincidencias muy dramáticas, sorprendentes e inverosímiles". Otra innovación consiste en la ubicación de los créditos iniciales a los cuatro minutos y medio del comienzo, no obstante, su diseño es sobrio: letras blancas sobre fondo negro. La puesta en serie y su consecuente efecto de desorden se origina desde el lugar poco común de los créditos iniciales que, aunque no formen parte de la narrativa, se deben considerar en la reconstrucción de la fábula, ya no por motivos cronológicos, sino por costumbre cinematográfica.

Las líneas punteadas (...... hacen referencia al relato principal del film, por lo menos porque abarca el $65 \%$ del tiempo total. Es precisamente la historia de Honey Bunny y Pumpkin / Vincent Vega y Jules Winfield la fragmentada y la que inicia in media res.

El juego de la puesta en serie se vuelve más complejo en la parte intermedia de la película. En primer término e inmediatamente después de la aparición del letrero que anuncia el relato de Vincent Vega and Marsellus Wallace's Wife, Tarantino ubica una breve secuencia de transición de alrededor de seis minutos entre este relato y el de The Gold Watch, aquí referido en líneas dobles ( ). Por los indicios en la ropa de los dos sicarios (Vega y Winfield), sabemos que es cuando ellos llegan al bar de Wallace que el relato principal ha terminado e inicia el segundo. Asimismo, esta secuencia está seguida de las acciones previas de Vega antes de encontrarse con la esposa de su jefe donde se inserta una especie de tratamiento musical del film sin relación lógica o cronológica con la narración. Finalmente, la secuencia es seguida por un inesperado flash back acerca de la infancia de Butch. La línea triple ( ) representa el relato de Vincent Vega y Mia Wallace, pero la acción más importante desde el punto de vista del montaje, es la secuencia musical, aquí nominada de tiempos desfasados, pues no se trata de un montaje paralelo ni tampoco de un flash back. Tarantino recupera otra tradición audiovisual: la del video-clip, la de un montaje en vaivén sin relaciones causales o temporales. Los intercortes están mediados por fundidos en negros muy suaves y largos (entre un segundo y dos), aunque la secuencia dura apenas un minuto con siete segundos, respeta el ritmo pausado de la canción. 
La línea más gruesa ( $)$ hace alusiơn al último gran relato, el de Marcelo Wallace y Butch, que representa el $31 \%$ del tiempo total de la película. La secuencia inicia con un largo flash back de catorce minutos, justo en el momento en que un amigo de guerra del padre de Butch le entrega a éste un reloj de oro, previo discurso irónico sobre los valores de la familia y el patriotismo norteamericano.

Ahora bien, la construcción de la fábula, a favor de ordenar la puesta en serie que tanto molestó a algunos espectadores, no sólo debe respetar la secuencia temporal, sino también la lógica de aparición de los textos, es decir, a la narrativa se le suma también un elemento aparentemente secundario, pero esencial en la inteligibilidad de la película: la ubicación de los créditos y de los didascálicos ${ }^{6}$, según la tradición cinematográfica.

En razón de lo anterior, la fábula de Pulp Fiction se puede expresar gráficamente así:

\section{Fábula narrativa}

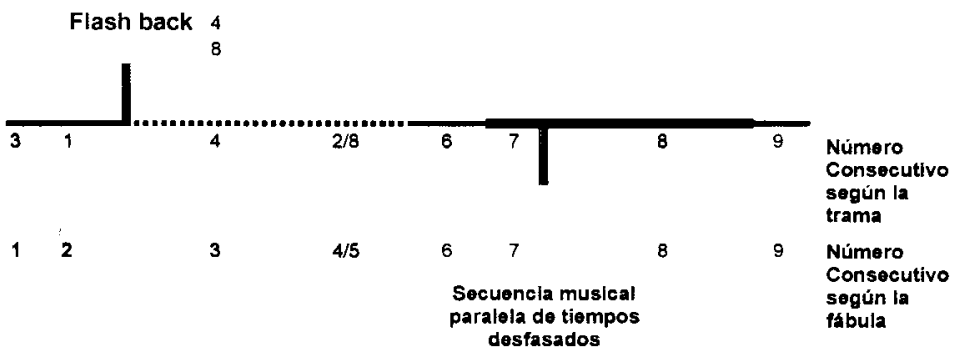

¿Esta organización cronológica hace más inteligible al film? No se puede esperar que el cine se parezca a la vida misma para entenderlo. Por mucho que nos esforcemos por trasladarlo a las formas del mundo exterior, este medio tiene una lógica propia que si se violenta, entonces también puede perder sentido. Si se ubicara el flash back inmediatamente después de los créditos, se le estaría exigiendo al espectador un esfuerzo desproporcionado por recordar lo ocurrido mucho tiempo atrás, asimismo, entre el flash back y las siguientes acciones no existe ninguna relación. En tal situación, sí podríamos hablar de un film desordenado.

${ }^{6}$ Según Casetti los didascálicos "son aquellos indicios gráficos que sirven para integrar todo lo que presentan las imágenes .... para explicar el contenido de las imágenes .... para pasar de una imagen a otra" (Casetti, 1991: 96) 
En contraste, si construimos la fábula no sólo respetando la temporalidad y la aparición de textos, sino también la lógica propia del flash back (la de aparecer cuando se le requiera), entonces la gráfica se modifica un poco:

Fábula narrativa más tradición cinematográfica

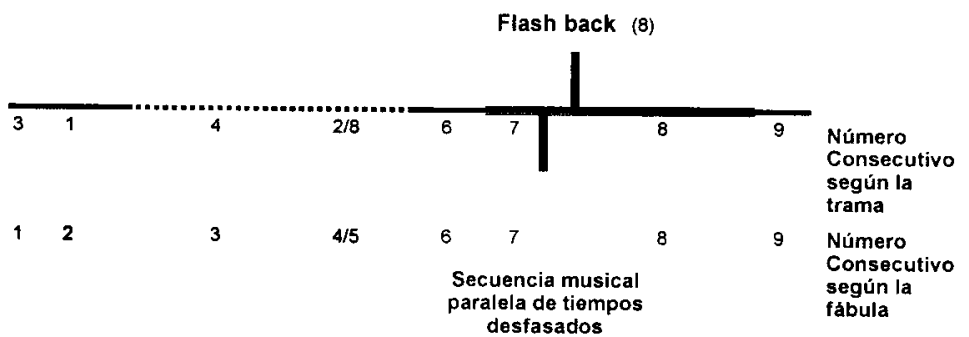

Con la finalidad de precisar mejor el análisis, a continuación se desscribe la reorganización cronológica, pero también lógica según los principios de inteligibilidad del film:

\begin{tabular}{|c|c|c|c|}
\hline $\begin{array}{c}\text { Orden } \\
\text { cronologico y } \\
\text { cinematográfico } \\
\text { de la fábula } \\
\end{array}$ & $\begin{array}{l}\text { Forma } \\
\text { de la } \\
\text { línea }\end{array}$ & $\begin{array}{l}\text { Descripción } \\
\text { de las acciones }\end{array}$ & $\begin{array}{c}\text { Orden } \\
\text { de la trama }\end{array}$ \\
\hline 1 & & Aparecen los créditos de inicio. & 3 \\
\hline 2 & & Explicación del vocablo $P$ ulp. & 1 \\
\hline$\because \cdots 3$ & & $\begin{array}{l}\text { Vincent y Jules se dirigen a cumplir } \\
\text { una misión de Marcelo: } \\
\text { asesinar a unos traficantes de drogas. }\end{array}$ & $\overline{4}$ \\
\hline$=4$ & & Secuencias paralelas. Vincent asesina & 2 \\
\hline$\ldots=05$ & & $\begin{array}{l}\text { al "hombre" de Wallace, después de } \\
\text { "limpiar" la escena del crimen, con la } \\
\text { ayuda de Wolf y Jimmy, desayunan en } \\
\text { el restaurante donde se encuentran } \\
\text { planeando el asalto Honey Bunny } \\
\text { y Pumpkin. }\end{array}$ & 8 \\
\hline$=6$ & & $\begin{array}{l}\text { Secuencia de transición. Jules y Vincent } \\
\text { llegan al bar de Wallace donde se } \\
\text { encuentran por primera vez con Butch. }\end{array}$ & 6 \\
\hline$\equiv 7$ & & $\begin{array}{l}\text { Inicia el relato de Mia-Vincent. } \\
\text { Se inserta la secuencia musical. } \\
\end{array}$ & 7 \\
\hline 8 & & $\begin{array}{c}\text { Flash back de la infancia de Butch, } \\
\text { continúa con las acciones de la pelea, } \\
\text { la huida del boxeador y el } \\
\text { encuentro Marcelo-Butch. }\end{array}$ & 8 \\
\hline 9 & & Créditos finales. & 9 \\
\hline
\end{tabular}


Después de esta reconstrucción de la fábula, ¿qué conclusiones obtenemos del análisis de la puesta en serie de la película?

1. Según la línea de acción punteada sólo se corta la historia principal y desde la secuencia de la transición, la trama coincide con la estructura narrativa clásica de una película (líneas dobles, triples y gruesas). La sensación de descontrol del espectador es producida por un ordenamiento intercalado de una historia dividida en su organización artística en tres grandes partes: dos en los primeros veinte minutos, y una a partir de la hora con cincuenta y un minutos. Si habláramos de desorden, éste podría ser ubicado en los extremos del film.

2. El flash back es otro elemento de dispersión de la atención, así como el título de la secuencia de The Gold Watch ubicado mucho tiempo después del inicio de esta secuencia.

3. La secuencia musical también juega con la puesta en serie y con la división de la atención del espectador, no por relaciones espaciales simultáneas, sino por temporalidades diferentes.

4. En el arreglo de la fábula, las secuencias dos y ocho no pueden ser ubicadas secuencialmente, sino de manera paralela.

5. La reconstrucción de una película sólo con base en el relato, no es suficiente para lograr la inteligibilidad del film según las reglas de la causalidad externa, por lo que es necesario remitirse a la tradición cinematográfica, en nuestro caso de presentación de créditos y de ubicación del flash back.

¿Qué es el desorden? Una estructura no lineal de la trama como afirma Ebert. La consecuencia inmediata es la imposibilidad de recordar y de establecer relaciones fácilmente. Esta estructura desorienta hasta al espectador especializado, sin embargo el sólo hecho de no saber qué pasa, es un buen síntoma para saber que el film cuestionó algunas de nuestras seguridades intelectuales. El rompimiento lineal del montaje, hizo que la película se convirtiera en una experiencia extraña, extraña porque no respetó ni la realidad ni la tradición de una trama según los principios aristotélicos de inicio, exposición, clímax y desenlace. En Pulp Fiction A no es primero que $B$, las causas no están antes que los efectos, sino que se trata de una organización fragmentada que sólo la mente puede seguir, reconstruir y comprender. 


\section{Memento $^{7}$ o contra la linealidad temporal.}

Si Pulp Fiction es una película compleja al romper con la continuidad del relato gracias a la fragmentación de grandes bloques narrativos, Memento se caracteriza por negar la realidad consecutiva del tiempo de la vida: no vamos a la muerte, la muerte regresa a la vida. Jean Epstein reflexionó sobre esta posibilidad de la máquina cinematográfica de pensar el tiempo de modo diferente, no sólo porque lo estira y condensa, sino también porque niega un hecho convertido en principio científico: la irreversibilidad de la marcha del tiempo:

El cinematógrafo ha destruido esta ilusión: muestra que el tiempo no es más que una perspectiva nacida de la sucesión de fenómenos, así como el espacio no es más que una perspectiva de la coexistencia de las cosas... Por eso pueden existir treinta y seis tiempos diferentes y veinte clases de espacios, e innumerables perspectivas particulares según las posiciones infinitamente distintas de los objetos y de su observador (Epstein, 1960: 41).

Precisamente esta multiperspectiva temporal parece ser el tema formal de la película de Nolan, ya sea por el tratamiento reversible del tiempo, ya sea por el uso de innumerables flash back, o bien, por intercalar tiempos cronológicos con otros reversibles, es decir, en franco contrasentido.

El objetivo, las categorías analíticas y el modo de abordar el film respecto al film anterior, no cambian y conducen también el análisis de esta segunda película. Revisemos, pues, la trama y la fábula:

\section{Trama}

Inicio

Dirección de la acción

Final (retrocede)

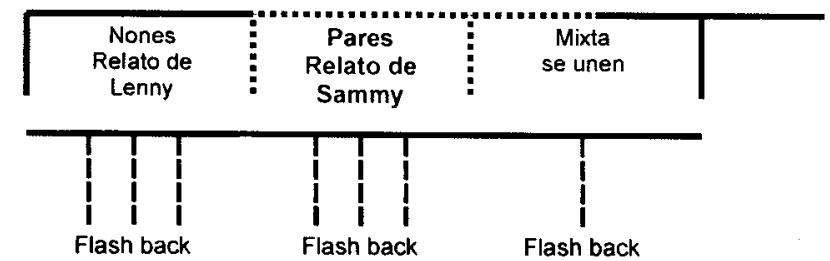
2000

${ }^{7}$ Ficha técnica: Memento (Amnesia), Christopher Nolan, Estados Unidos, 


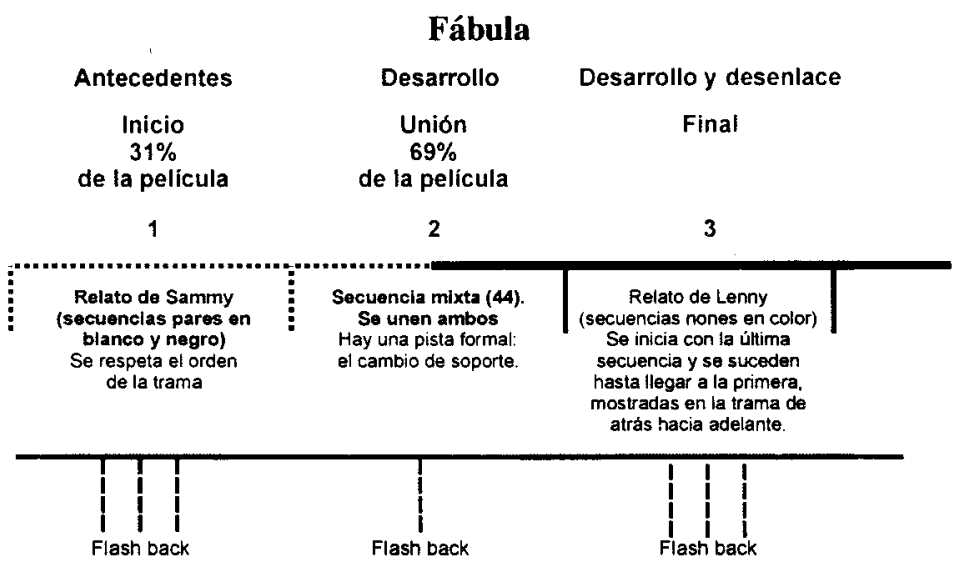

A las categorías utilizadas en Pulp Fiction, se le suma una más de carácter formal, por la importancia en la organización de la trama de Memento. Nos referimos al soporte, un elemento ubicado en la puesta en cuadro, es decir, en los parámetros expresivos controlados por el director. Los posibles soportes de un film son: blanco y negro, color, texturas o digital.

Nolan, no sólo divide dos grandes relatos recurriendo al uso de recursos narrativos, sino que también lo hace al echar mano de las innumerables posibilidades cinematográficas, en particular, al uso alternado del blanco y negro y color. No se trata, por supuesto, de un descubrimiento innovador, pues ya desde 1927, el director francés Abel Gance, utilizó los virados al azul y al sepia, sucedidos con el blanco y negro, en su asombrosa película épica, llamada Napoleón. Pero este uso no tenía un motivo vinculado directamente con el relato, más bien se trató de una experimentación formal, puramente cinematográfica, sin consecuencias en la narrativa de la película. Por el contrario, Nolan, sí hace un uso justificado de esta alternancia de soportes, no de manera tradicional: el blanco y negro para referirnos al pasado, a las ensoñaciones o a la fantasía, sino más bien, el blanco y negro para distinguir una historia de otra. En este sentido, de las 45 secuencias del film, todas las pares están filmadas en blanco y negro, mientras que las nones, en color. Sólo la última, en el orden de la trama, es mixta. Esta distinción formal permite al espectador alcanzar cierto nivel de inteligibilidad del film, además de otros indicios como veremos más adelante.

Memento está construida sobre la base de dos grandes historias: 
- nones: relato de Lenny desarrollado por las acciones propias de los personajes;

- pares: relato de Sammy, narrado en gran parte en voz over por Lenny ${ }^{8}$.

Las secuencias nones, todas en color, organizan la trama de manera reversible, el cine, lejos de mostrarse como un reflejo fiel de la realidad, nos inquieta por su exhibición del tiempo, no sólo de los tiempos simultáneos, sino del efecto convertido en causa. Por su parte, las secuencias pares se presentan de manera cronológica, de inicio a fin, es decir, el tiempo en su dimensión real donde a toda causa le corresponde un efecto. La secuencia 44 une ambos relatos, fusiona dos potencias temporales opuestas, pero sin ninguna colisión, más bien la fusión es armónica, tanto que prácticamente pasa inadvertido el cambio sutil del blanco y negro al color, cuando Lenny espera que se revele una fotografía instantánea del supuesto asesino de su esposa. A esta organización de pares y nones, de una historia que va y otra que regresa, se le debe agregar la existencia de 48 breves flash back repartidos en 14 de las 45 secuencias. Para los creyentes de una gramática cinematográfica, el siguiente dato es interesante, pues contradice cualquier intento normativo de los usos formales y expresivos del cine: el 75\% de los flash back son el color, ¿dónde quedan las ideas acerca del uso del blanco y negro reservado a la presentación de acciones pasadas?

Si reconstruimos la película en términos cronológicos, el orden de la presentación de las acciones sería el siguiente:

1. Se iniciaría con el relato de Sammy narrado en voz over por Lenny. Todas las secuencias pares en blanco y negro las vería el espectador a lo largo de 35 minutos ( $31 \%$ del film), es decir, el tiempo promedio que le lleva a una película clásica desarrollar los antecedentes.

2. Terminadas las 20 secuencias en blanco y negro, inmediatamente se presentaría la secuencia mixta 44 y justo donde el soporte cambia suavemente del blanco y negro al color, iniciaría la historia de Lenny, que no es otra que la venganza de la muerte de su esposa. Sin embargo, como la trama de Lenny está organizada de atrás hacia

${ }^{8}$ Tal vez, Sammy nunca existió y se trata de la vida de Lenny contada por él mismo, pero nosotros damos por hecho que, en la presentación de la trama, sí existio Sammy por un lado y Lenny por otro. 
delante, sería necesario continuar de la secuencia 44, a la 43 , a la 41 , a la 39 y así hasta llegar a la primera.

3. Los flash back, se respetarían, pues como vimos con Pulp Fiction, una respetuosa organización cronológica dificulta la comprensión del film.

Asimismo, existen elementos de legibilidad para conservar la transparencia del film, además del soporte. Se trata de indicios narrativos para que el espectador reconstruya el tiempo cinematográfico en tiempo real y establezca las relaciones causales pertinentes. Nos referimos a los inicios reiterativos de las secuencias en color. Por lo regular, se reitera en los primeros segundos de una secuencia, el final de la anterior, aunque sea desde un diferente emplazamiento de la cámara. Otros dos indicios son la vestimenta de Lenny y un arañazo en su mejilla izquierda, así como el cristal roto del automóvil de Lenny. Estos motivos narrativos son importantes porque el espectador ancla su interpretación del tiempo en evidencias visuales y evita perderse en la lógica reversible del film.

Por otro lado, existen dos secuencias que merecen una atención particular. Ya hablamos de una de ellas, la secuencia 44, mixta en dos sentidos: formal (cambio de soporte) y narrativa (une ambas historias), pero también proporciona un dato que puede cambiar radicalmente el sentido de la película: en un brevísimo flash back de sólo un segundo de duración, se ve a Lenny acostado con su esposa en la cama con el torso desnudo, está tatuado con los resultados de su investigación que lo conducirían a vengar la muerte de ella. En el resto de los flash back, cuando Lenny aparecía desnudo, nunca se mostró tatuado, únicamente en éste, lo cual contradice su propio relato y refuerza la hipótesis que él es Sammy, tal y como se lo dijo Teddy. De ser así, Lenny ha sido utilizado en ocasiones anteriores para matar a varias personas, siempre por el mismo motivo: vengar la muerte de su esposa. En el fondo, se trata de una conjetura viable, aunque sólo avisada en la película, nunca corroborada.

Otra secuencia fundamental en la comprensión de la película es la primera pues expone la lógica de la trama del relato en color. El recurso formal, en esta ocasión, no proviene de la cámara, sino del proyector, de la posibilidad de hacer correr una cinta de atrás hacia delante, igual que la organización reversible de la trama de Lenny. Esta secuencia está rodada en 15 planos cortos de 2.5 segundos en promedio, todos son encuadres de detalle: la nuca, la bala, la pistola, los rostros. Una gran parte de los inicios de las películas y de otras 
formas narrativas, suelen dar suficiente información al espectador como para hacerse una idea clara del final, en ocasiones puede ser un diálogo, en otras una imagen o un sonido. Nolan, lo hace mediante el montaje hacia atrás, es decir, hace una clara alusión a la estructura de la puesta en serie: isi una secuencia de alrededor de dos minutos, puede negar el principio secuencial del tiempo de la vida, por qué un film de dos horas, no puede hacer lo mismo? El resultado ya no es el reflejo de la vida en la pantalla, sino un cine-mente obligado a ir y venir en el tiempo, en los recuerdos y en los detalles.

\section{Derivaciones del análisis}

Cuando Münsterberg vio Neptune's Daughter alrededor de 1915, se clarificaron sus ideas acerca del funcionamiento de la mente. Como buen psicólogo experimental hablaba de leyes de la realidad y, por extensión, de leyes de la mente. Si bien el uso de este vocablo implica principios universales, en la actualidad es erróneo considerar que el cine se rige, al igual que el funcionamiento del cerebro, por reglas de la naturaleza humana. Las analogías cine-mente han sido una constante a lo largo de la historia del cine, basta recordar las consideraciones del cine como una experiencia onírica, o más recientemente, la capacidad cognitiva del espectador movilizada por una serie de pistas e informaciones que la película proporciona, capacidad estudiada ampliamente por el investigador norteamericano David Bordwell (1996).

Ahora bien, los mecanismos de la mente, sobre todo del recuerdo y de la fantasía, encuentran un símil muy poderoso en un recurso formal del cine aquí analizado: la puesta en serie. La puesta en serie, montaje o edición, permite romper con la linealidad del tiempo, con una regla absoluta hasta nuestros días: la marcha hacia la muerte, pues las mediciones del tiempo no dejan de ser creaciones simbólicas en función de un devenir común a todo ser vivo, no se trata del progreso, ni del hombre futuro, sino de la mortalidad.

No obstante nuestro cuerpo experimenta el tiempo de manera diferente a la mente, en el primero hay marcas temporales, descomposición física paulatina y constante, por el contrario, la mente puede ir hacia atrás o delante de la línea del tiempo, incluso de manera lateral. Memento, lo demuestra fácilmente, Lenny es la única persona capaz de ubicarse en tiempo real, es el sujeto de la enunciación, el tiempo se define sólo en función de su habla, de sus acciones. Lenny 
narra la historia de Sammy en voz over, le da continuidad a la acción presentada en imágenes pasadas, explica al espectador su método de vida, de recordar, pues sin esta capacidad no es más un ser humano. Nos enteramos también del presente en el que vive, pero nos obliga a sentir el esfuerzo por recordar mediante la estructuración de una trama organizada de atrás hacia delante. El espectador, divide su interés entre el presente de Lenny, el pasado de Sammy y la reversibilidad del tiempo, en suma, el cine no es la vida, sino la mente visualizada en una pantalla.

La fábula nos demuestra que tanto Pulp Fiction como Memento, podrían estar dispuestas cronológicamente, lo cual sería un verdadero desperdicio artístico, pero como se trata de películas a favor de la experimentación formal cinematográfica, para nosotros el deber ser del cine, permiten superar las concepciones tanto realistas como narrativas, pues este medio no se puede reducir ni a la reproducción de la realidad ni a ilustrar novelas o a representar cualquier otro género proveniente de la literatura o de la cultura de masas. El cine muestra un nuevo estado de las cosas y para ello utiliza sus propios recursos audiovisuales que, por suerte, se asemejan mucho al funcionamiento de la mente.

Ambas películas obligan al espectador a intentar alejarse del olvido y la confusión, pero para eso necesita establecer un sistema de memorización a favor de la comprensión de la película, tal y como lo hace Lenny con su vida. Asimismo la lógica del tiempo reversible, de la cámara hacia atrás, rompe todo nexo causal y supera los límites de la toma para abarcar a la totalidad de la película, pues como afirma Epstein, este cerebro mecánico reelabora de manera asombrosa las excitaciones espaciales y temporales que recibe.

\section{Glosario básico}

Análisis cinematográfico. Para Lauro Zavala (2003), el análisis cinematográfico consiste en una puesta en práctica de estrategias de estudio de los elementos específicos de una película para reconocer algún subtexto.

Aparato cinematográfico. La noción de aparato cinematográfico fue desarrollada por Jean-Louis Baudry (1974) en el contexto de las teorías psicoanalíticas y de las ideologías. El aparato cinematográfico está conformado por un conjunto de maquinarias e instituciones que van desde los modos de producción de una película hasta las 
condiciones psicológicas del espectador. Este teórico francés propone un espectador arquetípico, víctima de una pantalla-sueño y de la dominación ideológica de las instituciones sociales.

Sin embargo, en estas líneas nuestra pretensión ha sido otra, pues cuando hemos hablado de la experiencia del aparato nos hemos referimos al complejo de elementos proveniente de la cámara y del sonido, coordinados en la elaboración de una película con el fin de producir un efecto narrativo, temático o emotivo en la mente del espectador. Nos hemos centramos en los medios del cine, pues en sí ya forman un conjunto de varios dispositivos que concurren en la tarea de introducir en una experiencia intensa de vida al público del cine.

Didascálicos. Según Casetti (1991) los didascálicos son aquellos indicios gráficos que sirven para integrar todo lo que presentan las imágenes, para explicar el contenido de las imágenes, o bien, para pasar de una imagen a otra.

Fábula. Es en la reorganización secuencial y cronológica de los acontecimientos que elabora el espectador a partir de la disposición artística de un film.

Flash back. Una imagen o secuencia que muestra un evento anterior del que está siendo descrito. Se trata de un recurso narrativo que permite cierto grado de flexibilidad en la construcción de la trama.

Forma cinematográfica. Todo aquello que puede ser percibido por los sentidos del espectador, más allá de las acciones de los personajes. A grandes rasgos la forma cinematográfica se puede descomponer en tres grandes puestas: en escena, en cuadro y en serie.

Fundido en negro. Una imagen desaparece o se obscurece progresivamente.

In media res. Cuando el relato de una película no inicia cronológicamente, sino en cualquier momento del desarrollo, $o$ incluso en el desenlace, de la trama.

Indicios. Una clase de signo que necesita de su referente para existir. Por ejemplo, el humo que se refiere a fuego, la huella que es rastro de un animal.

Montaje. Proceso técnico de selección, ensamblado y arreglo de las imágenes y sonidos de una película. A lo largo de la historia del cine, el montaje ha sido visto como uno de los elementos esenciales de la cinematograficidad. Las clasificaciones han sido también muy variadas, por ejemplo, el montaje paralelo que muestra dos o más acciones simultáneas en el tiempo, pero en espacios diferentes, $o$ bien, 
el montaje de tiempos desfasados sin relaciones causales, temporales o espaciales.

Photoplay. Sinónimo de cine para Hugo Münsterberg. El photoplay ajusta la historia de la vida humana a las formas de la mente: atención, memoria e imaginación. Cada una de estas posibilidades del pensamiento humano tiene un símil con algún recurso expresivo del cine: la atención con el primer plano, la memoria y la imaginación con el montaje.

Plano. El término en un inicio distinguió las tomas espaciales en el rodaje, partiendo de una línea perpendicular a la cámara a través de la cual se divide al cuerpo humano. Actualmente esta división es muy conocida y se puede resumir en planos abiertos, medios y cerrados, según la porción que ocupe el cuerpo humano en relación con su entorno.

La idea de plano también posee características espaciales y en este medida se ha enfrentado al plano fijo contra el móvil. El plano móvil se popularizó a finales de los años cincuenta con la utilización del plano-secuencia, es decir, un plano que dura el equivalente de una secuencia sin que medie corte alguno.

También se ha concebido al plano como un segmento del montaje toda vez que abarca una escena rodada de una sola vez, lo que involucra al tiempo y al espacio narrativo.

Desde el punto de vista teórico, se ha visto en el plano la unidad mínima significativa del cine, pues un conjunto de imágenes en el cine conforma un plano. En consecuencia, decir plano o imagen cinematográfica es decir exactamente lo mismo.

Primer plano. Toma de acercamiento generalmente al rostro de un personaje.

Secuencia. Es una unidad espacio-temporal completa y fragmentada en un sinnúmero de tomas, pero reconstruida gracias al montaje.

Soporte del film. Término técnico para referirse al material (celuloide) y a sus características: sensibilidad, croma, contraste, resolución. El soporte puede manipularse tanto química como digitalmente, dando diversos resultados artísticos: texturas, múltiplesexposiciones, tonos fríos (azules) o cálidos (rojos), entre muchos otros.

Trama. También conocida como syuzhet. Consiste en la organización artística de la película tal y como fue organizada por el director o el equipo de producción no sólo atendiendo a principios narrativos, sino también formales (puesta en escena, cuadro y serie). 
Toma. Conjunto de imágenes filmadas en un solo accionar de la cámara.

Virado. Cambio de color de una imagen monocromática mediante la aplicación de ciertos procesos químicos. Tanto en la historia de la fotografía como del cine, los virados más comunes han sido al sepia y al azul.

\section{Bibliografía}

Albéra, Francois (compilador) (1998). Los formalistas rusos y el cine: la poética del filme. Paidós. España.

Andrew, Dudley. (1978) Las principales teorias cinematográficas. Gustavo Gili, segunda edición. Barcelona.

Balázs, Béla (1978). El film: Béla Balázs: evolución y esencia de un arte nuevo. Gustavo Gili. Barcelona.

Baudry, Jean-Lois (1974). "Idelogical effects of the basic cinematographic apparatus" and "The apparatus:

metapsychological approaches to the impression of reality in cinema", en Mast, Gerald, Marshal Cohen and Leo Braudry. Film theory and criticism. USA.

Bellour, Raymond (2002). The Analysis of Film. Indiana University Press. USA.

Bordwell, David 1996). La narración en el cine de ficción. Barcelona, Paidós.

Buckland, Warren (1998).Teach Yourself: Film Studies. Hodder \& Stoughton. USA.

Casetti, Francesco y Federico Di Chio. (1991) Cómo analizar un film. Paidós. Barcelona.

Darley, Andrew (2002). Cultura visual digital: espectáculo y nuevo géneros en los medios de comunicación. Paidós. Barcelona.

Epstein, Jean (1960). La inteligencia de una máquina. Nueva Visión. Argentina.

Langdale, Allan (2002). Hugo Münsterberg on Film. The Photoplay: A Psichological Study and Other Writings. Routledge. USA.

Lotman, Yuri (1973). Estética y semiótica del cine. Gustavo Gili. Barcelona.

Metz, Christian. (2002) Ensayos sobre la significación en el cine. Volúmenes uno y dos.

Montiel, Alejandro (1992). Teorías del cine. Un balance histórico. 
Barcelona, Montesinos, Biblioteca de Divulgación Temática, núm. 60.

Münsterberg, Hugo (1970). The Photoplay. Arno Press \& New York Times. USA.

Tosi, Virgilio (1987). Manual de cine científico. UNAM-UNESCO. México.

Zavala, Lauro (2003) Elementos del discurso cinematográfico.

UAM-X. México 